\title{
Aguas termales y mineromedicinales en el valle bajo del río Mundo (Hellín, Tobarra, Prov. de Albacete). Aspectos geográficos, hidrogeológicos, arqueológicos, históricos y etnográficos.
}

\author{
J. F. JORDAN MONTES * \\ C. Conesa Garcia *
}

INTRODUCCIÓN

España es un país pródigo en manantiales de aguas calientes y mineromedicinales. Los primeros constituyen, en algunos casos, claros indicios de geotermismo, que revelan la existencia de yacimientos más o menos profundos de agua o vapor a alta temperatura. Con bastante frecuencia, se trata de áreas cuya sismicidad asegura la permeabilidad de almacén, y que presentan un volcanismo joven ligado a grandes fallas de zócalo. La zona más prometedora para obtener yacimientos de alta temperatura corresponde al limite entre el Subbético y Bético s. str. en las Cordilleras Béticas, ocupando una franja continua entre ambos dominios a lo largo de las provincias de Murcia, Granada y posiblemente extendiéndose hacia Málaga. El espesor de la cobertera neógena y la existencia de rocas almacén más profundas asegura la existencia y conservación de este tipo de yacimientos, al tiempo que las relaciones $\mathrm{Na} / \mathrm{K}$ dan a ve-

\footnotetext{
* Universidad de Murcia.
} 
ces concentraciones que presuponen temperaturas del agua superiores a $100^{\circ} \mathrm{C}$ en profundidad ${ }^{1}$, por ejemplo en Baños de Mula (Murcia).

El termalismo de la comarca de Hellin-Tobarra dista mucho, desde un punto de vista geológico, del existente en la región de Murcia; las formaciones neógenas inscritas en el Prebético, dominio al que pertenece dicho área, y la menor importancia del volcanismo reciente, así como los datos hidroquímicos, desechan la idea de que exista agua de tan alta temperatura en profundidad. $Y$ en superficie, el agua de los manantiales «termales" suele oscilar entre 20 y $30^{\circ} \mathrm{C}$. No obstante, la calidad química de algunos de ellos, incluidos en el presente estudio, les proporciona características medicinales comparables a las de los conocidos balnearios murcianos de Archena ${ }^{2}$, Fortuna ${ }^{3}$, Alhama ${ }^{4}$, Mula ${ }^{5}$, etc., cuyas aplicaciones hidroterápicas han tenido gran importancia desde la romanización.

El estudio sobre las aguas termales y mineromedicinales se desarrolló en la Península a fines del siglo XVIII y durante todo el siglo XIX a causa

1 E.N. ADARO DE INVESTIGACIONES MINERAS, S.A. (1974): Investigación de Recursos Geotérmicos de la España Peninsular. Madrid, INI, págs. 3-72.

${ }^{2}$ Sobre el balneario de Archena hay multitud de títulos. Sin pretender en ningún caso ser exhaustivos, destacamos: CERDAN, F., Disertación físico-médica de las virtudes medicinales, uso y abuso de las Aguas thermales de la villa de Archena. Murcia 1760.

LóPez de Arala, I., Poema phísico de los Baños calientes de la villa de Archena en el reyno de Murcia. Murcia 1777. BreIX, J., Disertación Histórica, fisica, analítica, medicinal, moral y metódica de las aguas thermo-potables de la villa de Archena. Reyno de Murcia. Cartagena 1801. Alıx, J., Memoria sobre las aguas medicinales de Archena Murcia 1818. Sanchez de las MATAS, N., Memoria sobre los baños y aguas medicinales de Archena. Madrid 1846. Zaval.A, J. M., Aguas minero-medicinales de Archena. Madrid 1875.

Los estudios más recientes lo integran las obras de LÓPEZ DE AZCONA, J. M., «Estudios sobre el balneario de Archena», Real Academia de Farmacia. Memoria, n. 12. 1986. MedinA Tornero, M. E., Historia de Archena. Murcia 1990 (en especial las páginas 75-85 y 549-584).

${ }^{3}$ Para el balneario de Fortuna, Chacel, J., Memorias sobre los baños de Fortuna. 1864. Carrio Grifol, J., Baños de Fortuna. 1871. Aragon Ovejero, E., Breve memoria de los baños de Fortuna. 1872. Cascales y Font, J., Aguas y baños termales de Fortuna. Barcelona 1876. Grau, J., Memoria médida de las aguas de Fortuna. 1879. Maso Bru, A. y Arnus Fortuny, M., Hidrologia médica de Fortuna. 1879.

Para toda la bibliografia, consultar el último trabajo de González BLANCo, A. y AMANTE SANCHEZ, M., "El balneario de Fortuna y la cueva Negra", presentando en este mismo congreso.

${ }^{4}$ Sobre el balneario de Alhama, PovedA, A., Disertación físico-química y análisis de las aguas minerales de Alhama del reino de Murcia, 1797. Y también, CASTILLo Y EspinosA, J. M., Memoria acerca de las aguas y baños termominero-medicinales de Alhama de Murcia. Murcia 1848. Y la aportación reciente de Baños Serrano, J.; Munuera Marin, D. y Ramirez Águila, J. A., «Aprovechamiento agrícola de las aguas termales en Alhama de Murcia. Captación, transporte y almacenaje», El agua en zonas de áridas: arqueologia e historia. Coloquio de Historia y Medio Físico. Almería 1989. Tom. II, págs. 523-542. Almería 1989.

${ }_{5}$ Junto a los baños de Mula, hay que citar los de la Isla Plana en Mazarrón, la Fuensanta en Lorca, los de Gilico,... etc. 
del auge de los medios de transporte, en especial del ferrocarril, que permitieron a la burguesía acceder a unos servicios identificados con un incremento del nivel de vida y del consumo. Los avances en la medicina y en la higiene, el gusto por los estudios geográficos y por los viajes y la apertura de la mentalidad ilustrada, favoreció en buena medida el uso y disfrute de los balnearios.

En el valle bajo del río Mundo hubo cuatro puntos de cierta fama provincial y aún regional. El del Azaraque, con aguas termales a muy baja temperatura. El del Cenajo, con similares características respecto a la temperatura del agua y que, probablemente, fue el más modesto. El de la Pestosa (o Apestosa), no termal sino mineromedicinal que fue el de mayores dimensiones y el mejor dotado de medios técnicos y humanos. $Y$, por último, el de Santa Quiteria al que la mentalidad popular relaciona con apariciones milagrosas; sus aguas sólo eran mineromedicinales. Los dos primeros se localizan en el término municipal de Hellín y los restantes en el de Tobarra.

Ninguno de estos balnearios o aguas mineromedicinales aparece citado en las grandes obras generales que tratan del tema desde finales del siglo xVII y durante el XVIII. Ello revela que carecian de fama más allá de las fronteras locales o que su utilización debe iniciarse en épocas más recientes ${ }^{6}$.

\section{LOCALIZACIÓN Y DATOS DESCRIPTIVOS DE LOS PUNTOS DE AGUA}

El manantial de «La Pestosa» se sitúa $3 \mathrm{Kms}$ al NO del núcleo de Tobarra y menos de $1 \mathrm{Km}$ al $\mathrm{N}$ del río Mundo. Se trata de una balsa natural de paredes y fondo limoarcilloso, de $70 \mathrm{~m}^{2}$. De la balsa parte, en dirección So, una galeria de unos $500 \mathrm{~m}$ de longitud que conduce a un canal de cemento, a partir del cual se distribuye el agua. El caudal oscila entre los

\footnotetext{
${ }^{6}$ Limon Montero, A., Espejo cristalino de las aguas de España, hermoseado y guarnecido con el marco de variedad de Fuentes y Baños,... etc. Alcalá de Henares 1697. Posteriormente, la obra de Gómez de Bedora y Paredes, P., Historia Universal de las fuentes medicinales de España, sitios en que se hallan, principios de que constan, análisis y virtudes de sus aguas, el modo de administrarlas,... etc. Santiado de Compostela 1765.

También, Rubio, P. M., Tratado de las fuentes medicinales de España. 1883. Ya en el siglo $X X$, IGM: Relación de los manantiales minero-medicinales de España. 1913.
} 
20 y $30 \mathrm{l} / \mathrm{s}$, siendo empleado actualmente para el riego de unas 20 Has dedicadas a hortalizas y frutales. Apenas a medio kilómetro de este manantial se encuentra, hacia el este, la Fuente de Las Marañas, balsa natural de roca calcárea de unos $40 \mathrm{~m}^{2}$ de superficie, en la que el agua brota a $5 \mathrm{l} / \mathrm{s}$ como promedio.

También en el municipio de Tobarra se ubican Los Baños de Santa Quiteria, balsa natural alimentada por un caudal medio de $0,3 \mathrm{l} / \mathrm{s}$, que dispone de una serie de surcos de drenaje labrados en terrenos impermeables muy salitrosos. Su utilización agrícola requiere un mejor drenaje superficial.

Por último, el manantial del Azaraque y los próximos al Cenajo pertenecen al Término de Hellín. El primero se localiza $1,5 \mathrm{Km}$ al $\mathrm{S}$ de Agramón. Es una balsa de grandes dimensiones $\left(900 \mathrm{~m}^{2}\right.$ de superficie), de paredes cementadas. La altura de la lámina de agua varía entre 0,6 y 2 metros, y los caudales entre 20 y $40 \mathrm{l} / \mathrm{s}$. Los restantes puntos corresponden a surgencias de agua en fondos arenosos de rambla y materiales triásicos, presentando un caudal generalmente bajo $(0,5-1 \mathrm{l} / \mathrm{s})$ cuando no existe conexión con las aguas del Cenajo. De hecho el importante caudal del punto 25345-007 $(200 \mathrm{l} / \mathrm{s})$ se debe a fugas o migraciones producidas junto a la presa del citado embalse.

\section{EMPLAZAMIENTO GEOLÓGICO DE LOS MANANTIALES}

El balneario de la Pestosa se localiza al pie de la Sierra de los Navajuelos, en un sector de calizas y margas grises pliocenas, que yacen sobre un conglomerado poligénico y arcillas rojas con intercalaciones calcáreas correspondientes al Mioceno Terminal. Situado apenas $1,5 \mathrm{Km}$ al SE del Pico Abenuz, cuenta con una superficie vertiente constituida por terrenos bastante permeables: dolomías y calizas de edad jurásica y materiales detriticos (arenas, conglomerados) cuaternarios. El apelativo "Pestosa" se debe a la existencia, en este área, de azufre de origen sedimentario asociado a los depósitos margosos del Mioceno Superior.

El manantial conocido como Los Baños de Sta. Quiteria se emplaza $1 \mathrm{Km}$ al S de Mora de Sta Quiteria, en terrenos biocalcareníticos que, por el sur, pasan lateralmente a margas arenosas. Por el oeste limitan con la formación diapirica de Santiago de Mora, constituida por arcillas rojas y yesos de edad triásica. $Y$ por el este toma contacto mecánico con calizas y margocalizas del Malm y conglomerados, arenas y arcillas albien- 
ses. Todo este conjunto oriental aparece afectado por fallas de dirección $\mathrm{NE}-\mathrm{SO}$ y E-O, que explican el emplazamiento de dicha fuente.

El manantial del Azaraque corresponde a una surgencia en materiales margosos con alternancia de calizas tableadas del Mioceno Superior. Su proximidad a los depósitos aluviales (arenas y limos con cantos) del río Mundo, $3 \mathrm{Kms}$ aguas arriba del embalse de Camarillas, hace que ocasionalmente, en las etapas de crecida, se vea algo afectado por la hidrodinámica de este tramo del río. En profundidad es alimentado por las aguas infiltradas en la vertiente norte de la Sierra de los Donceles (terrenos calizos, dolomíticos y detríticos), y en los parajes de Losares y Pedreras, donde afloran principalmente areniscas y biocalcarenitas.

Finalmente, de los tres manantiales existentes al NE del embalse del Cenajo, el más septentrional (25345009 según numeración del ITGE) surge en depósitos aluviales cuaternarios, después de atravesar la serie calizo-dolomítica del Dogger. El punto intermedio (25345008) aflora en terrenos con facies del Keuper, o sea constituidos por arcillas, limonitas, margas yesiferas, entre las que se distinguen potentes paquetes de yesos, que han favorecido los procesos de diapirismo en la zona. En cambio, el agua del tercer manantial (25345007) brota en el fondo de una rambla, en un lecho de arena y conglomerado calizo. El considerable aumento de su caudal desde la etapa anterior a la construcción de la presa del Cenajo (módulo aproximado: $0,5 \mathrm{1} / \mathrm{s}$ ) hasta el posterior período de regulación (200 1/s en diciembre de 1970) hace pensar en una posible fuga de aguas del embalse a través de los materiales del Dogger y del Mioceno Superior.

\section{CONTEXTO HIDROGRÁFICO}

Antes de adentrarnos en el termalismo del SE de la provincia de Albacete y de sus aguas minero-medicinales, hay que indicar una serie de elementos para comprender mejor la presencia del agua.

Durante milenios y siglos, prácticamente hasta finales del XIX y principios del $x x$, buena parte del territorio provincial estuvo salpicado de decenas de lagunas y lagos, temporales o permanentes. Aquellas masas de agua se caracterizaban por su endorreismo y en torno a su existencia se creó un universo de leyendas, creencias, romerias y curaciones. Hoy en 
día, tan sólo quedan pequeños vestigios de tales aguas superficiales y almarjales ${ }^{7}$.

La abundancia de los recursos hídricos subterráneos en Albacete se origina por la presencia casi continua de calizas, roca muy apta para constituir acuíferos, y por los niveles arcillosos del Triásico, impermeables y que permiten la acumulación del líquido ${ }^{8}$.

Las lagunas antes mencionadas constituyeron, junto a los manantiales termales, espacios sacralizados y santos por los nativos y las diferentes culturas que aprovecharon sus recursos y posibilidades. En sus aguas habia, y hay, multitud de sales y minerales que les confieren semejantes propiedades medicinales a las que se encuentran en los manantiales de procedencia subterránea.

Conocemos las salinas de Fuente Albilla con probables orígenes romanos. En épocas posteriores, sobre todo desde el xvI, su sal fue utilizada en un amplio abanico de necesidades: complemento en la alimentación del ganado, obtención de pólvora, conservación de alimentos, purgantes, abono natural en los campos,... 9 .

En la laguna del Saladar (La Higuera, Corral Rubio) o en la de Pétrola, los habitantes de las comarcas limitrofes acudian con sus bestias de carga, tiro y labor para sumergirlas en sus aguas. Asi, «se curaban las mataduras" o rozaduras y heridas que los animales (caballos, mulos y asnos) se hacian en las tareas agropecuarias ${ }^{10}$. Ambas formaciones lacustres están inmersas en áreas endorreicas con subsuelos impermeables. La intensa evaporación, la aridez del clima y la composición del suelo, originan eflorescencias salinas y un alto contenido de minerales en el agua ${ }^{11}$.

\footnotetext{
${ }^{7}$ Herreros Ruiz, J. A., Introducción al estudio de las zonas húmedas de la provincia de Albacete y su avifauna acuática. Albacete 1987, 132 págs. Es necesario también consultar el artículo de López Bermúdez., $F$., «E| sector pantanoso al W de Albacete y su desecación», Al-Basit, n. ${ }^{\circ}$ 5, págs. $69-110,1978$.

${ }^{8}$ Castano Fernández, S.; López Ros, J., y de Mora Moreno, J., "Itinerarios geológicos de la provincia de Albacete-Tobarra, Hellín, Minateda, Cancarix, La Celia", Al-Basit, n. ${ }^{\circ}$ 16, págs. $79-125,1985$

${ }^{9}$ Sobre las salinas de Fuente Albilla, Almendros Toledo, J. M.; "Algunas notas sobre las salinas de Fuentealbilla», Al-Basit, n. "17, págs. 19-62, 1985.

${ }^{10}$ Esta valiosa información fue recogida en prospección etnológica en el invierno de 1991, de boca de pastores que recorrían las orillas de la laguna de Pétrola.

${ }^{11}$ Existe en la actualidad una importante bibliografía inicial recogida en la revista AlBasit. Para la laguna Salada de Pétrola ver: Castaño Fernández, S.; López Ros, J., y Mora MoReno, J., «ltinerarios geológicos de la provincia de Albacete: Chinchilla de Monte Aragón y Pétrola», Al-Basit, n. ${ }^{\circ} 18$, págs. 63-104. Albacete 1986. Por último, para la laguna de $\mathrm{E}$ Saladar situada en La Higuera (Corral Rubio), López Ros, J., y MORA MORENo, J., «tinerarios
} 
Los manantiales termales en la comarca fueron tratados en los comentarios a las hojas geológicas del territorio. En la hoja de Hellin ${ }^{12}$ se declara que las aguas de La Pestosa eran útiles para aliviar las enfermedades reumáticas y cutáneas aunque los $15 \mathrm{l} / \mathrm{s}$ también se destinaban al riego. En Santa Quiteria el caudal se reducia a $6 \mathrm{l} / \mathrm{s}$, siendo las aplicaciones hidroterápicas muy similares.

En el área elegida para realizar el estudio existen igualmente varias decenas de manantiales y rezumaderos de muy diferentes caudales y aprovechamientos. En prácticamente todos ellos se intuyen y se aprecian con nitidez los esfuerzos de las culturas prehistóricas ${ }^{13}$ por asentarse en sus inmediaciones. Nos referimos primero a las industrias líticas del Paleolítico Inferior y Medio localizadas en la Fuente de Hellín, en el arroyo de Pedernaloso o en la fuente del Polope, por ejemplo. En la cabecera del arroyo del Pedernaloso, donde nace una fuente, se instaló un extenso taller al aire libre, beneficiándose de los nódulos de sílex que allí se encuentran y de la corriente de agua. Los yacimientos en Ilanura del Eneolítico (Fuente de Isso) prefirieron lagunas donde obtener plantas susceptibles de trabajos textiles, caza y pesca. Los poblados del Bronce Medio y Final no dudaron en elegir mesetas, picachos y promontorios que controlaran las fuentes de los distintos parajes. Su distancia respecto al agua muy rara vez excede de los 1.000 o $2.000 \mathrm{~m}$. En el mundo ibérico el abastecimiento del agua obligó a semejantes consideraciones en la ubicación de las ciudadelas. Las villae romanas tampoco estuvieron exentas de la necesidad de un manantial caudaloso y constante para suministrar el agua a los sectores de servicios y a la residencia de los amos. Así se desprende de las observaciones realizadas sobre el terreno en las villae de Hellín, del Polope (Tobarra), del Prao de Isso, de Agra,... etc.

\footnotetext{
geológicos de la provincia de Albacete: Fuente Álamo, Montealegre del Castillo, la Higuera, Corral Rubio, Higueruela y Almansa", Al-Basit, n. ${ }^{\circ} 24$, págs. 153-203, 1988.

En la laguna del Saladar se observan unas construcciones que recuerdan sin duda la presencia de un viejo balneario (probablemente los de $S$. José) que merecen un estudio pormenorizado. Es una llamada de atención.

${ }^{12}$ Memoria explicativa de la Hoja n. ${ }^{\circ} 843$ (Hellin) del Mapa Geológico Nacional. Escala 1:50.000, IGME. Madrid 1936. Téngase en cuenta que los caudales registrados y mencionados en el comentario, en este caso, corresponden a los años treinta.

${ }^{13}$ Jordan Montes, J. F., El poblamiento prehistórico en la comarca de Hellin-Tobarra (Tesis de licenciatura. Inédita). Murcia 1981.
} 


\section{CARACTERISTICAS QUIMMICAS DE LAS AGUAS}

\subsection{Puntos de muestreo}

En el cuadro 1 se muestran los resultados obtenidos por la E.N. ADARO para un total de cinco muestras correspondientes a los manantiales estudiados. Tres de ellos sólo disponen de un análisis: Las Marañas, Sta. Quiteria (ambos muestreados en diciembre de 1970) y el manantial situado al NE del Cenajo (25345009), cuyas determinaciones químicas se refieren a julio de 1971. Los dos restantes, La Pestosa y Azaraque cuentan con análisis relativos a invierno y verano.

\subsection{Conductividad y residuo seco}

Los valores de conductividad eléctrica (C.E.) encontrados oscilan desde los $1.655 \mu \mathrm{mhoss} / \mathrm{cm}$ a $25^{\circ}$ en la fuente de Las Marañas, localizada en

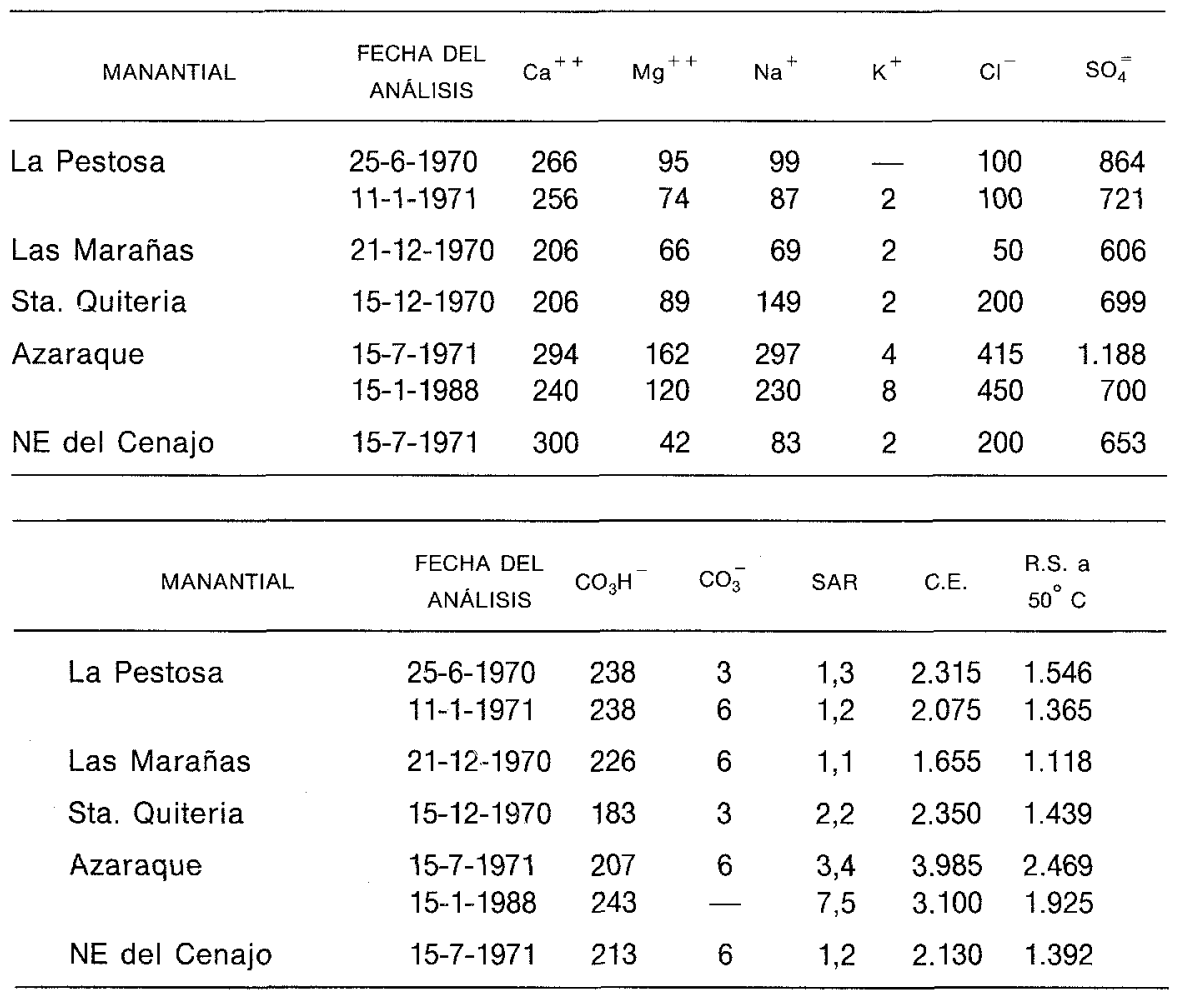

- Resultados en $\mathrm{mg} / \mathrm{l}$, salvo el índice de SAR y la C.E., expresada en $\mu \mathrm{mhos} / \mathrm{cm}$ a $25^{\circ} \mathrm{C}$. Cuadro 1. Datos de hidroquímica de los manantiales estudiados. 
Aguas termales y mineromedicinales en el valle bajo del río Mundo ...

conglomerados del Mioceno Superior, junto al balneraio de La Pestosa, hasta los $3.985 \mu \mathrm{mhos} / \mathrm{cm}$ en el manantial del Azaraque, que se emplaza sobre margas con elevado contenido en sales. No obstante, salvo este último caso, el resto de los puntos de agua ofrecen valores relativamente uniformes, comprendidos entre los 1.600 y los $2.300 \mu \mathrm{mhos} / \mathrm{cm}$.

El residuo seco (R.S.) varía proporcionalmente a la conductividad eléctrica, correspondiendo los valores máximos y mínimos a los mismos puntos citados.

En combinación con el resto de parámetros químicos y con la calidad física de estas aguas, ofrecen en general buenas condiciones terapéuticas. Sin embargo, en algunos casos (La Pestosa o Sta. Quiteria en los meses de verano, y sobre todo Azaraque) rebasan los valores máximos tolerables para el consumo humano, según se desprende de los umbrales fijados en la Reglamentación Técnico-sanitaria para el abastecimiento y control de calidad de aguas potables, aprobada por Real Decreto 1423/ 1982 (B.O.E. 29-6-1982). De acuerdo con esta normativa, el residuo seco permisible para considerar el agua como potable se establece en 1.500 $\mathrm{mg} / \mathrm{l}$; entre ambos parámetros existe una correlación lineal definida por la ecuación R.S. $(\mathrm{mg} / \mathrm{l})=0,576 \mathrm{C} . \mathrm{E} .(\mu \mathrm{mhos} / \mathrm{cm})+159$, con un coeficiente de correlación de $r=0,996$.

\subsection{Cationes y aniones}

Al igual que ocurre con los parámetros anteriormente descritos, los iones presentan también, a excepción de Azaraque, cierta homogeneidad. La fig. 1 , en la que se representa el diagrama de PIPER ${ }^{14}$ es suficientemente ilustrativo al respecto.

La totalidad de las muestras analizadas tienen el ión $\mathrm{SO}_{4}^{=}$como anión más abundante, con valores comprendidos entre 606 y $1.188 \mathrm{mg} /$; a continuación le sigue el ión $\mathrm{CO}_{3} \mathrm{H}^{-}$que, salvo en los casos de Sta Quiteria y Azaraque, domina sobre el ión $\mathrm{Cl}^{-}$, superando en todo momento los 180 $\mathrm{mg} / \mathrm{l}$. Por último, los cloruros alcanzan una cifra preocupante sólo en el manantial de Azaraque (entre 415 y $450 \mathrm{mg} / \mathrm{l}$ ), donde el agua es bastante salobre y no debe utilizarse más que en condiciones de uso favorables, tales como suelos permeables, fácil drenaje y cultivos de buena toleran-

\footnotetext{
14 PIPER, A. M., "A graphic procedures in the chemicals interpretation of water analysis", Am. Geoph. Union Trans, V, 25 págs. 1944.
} 


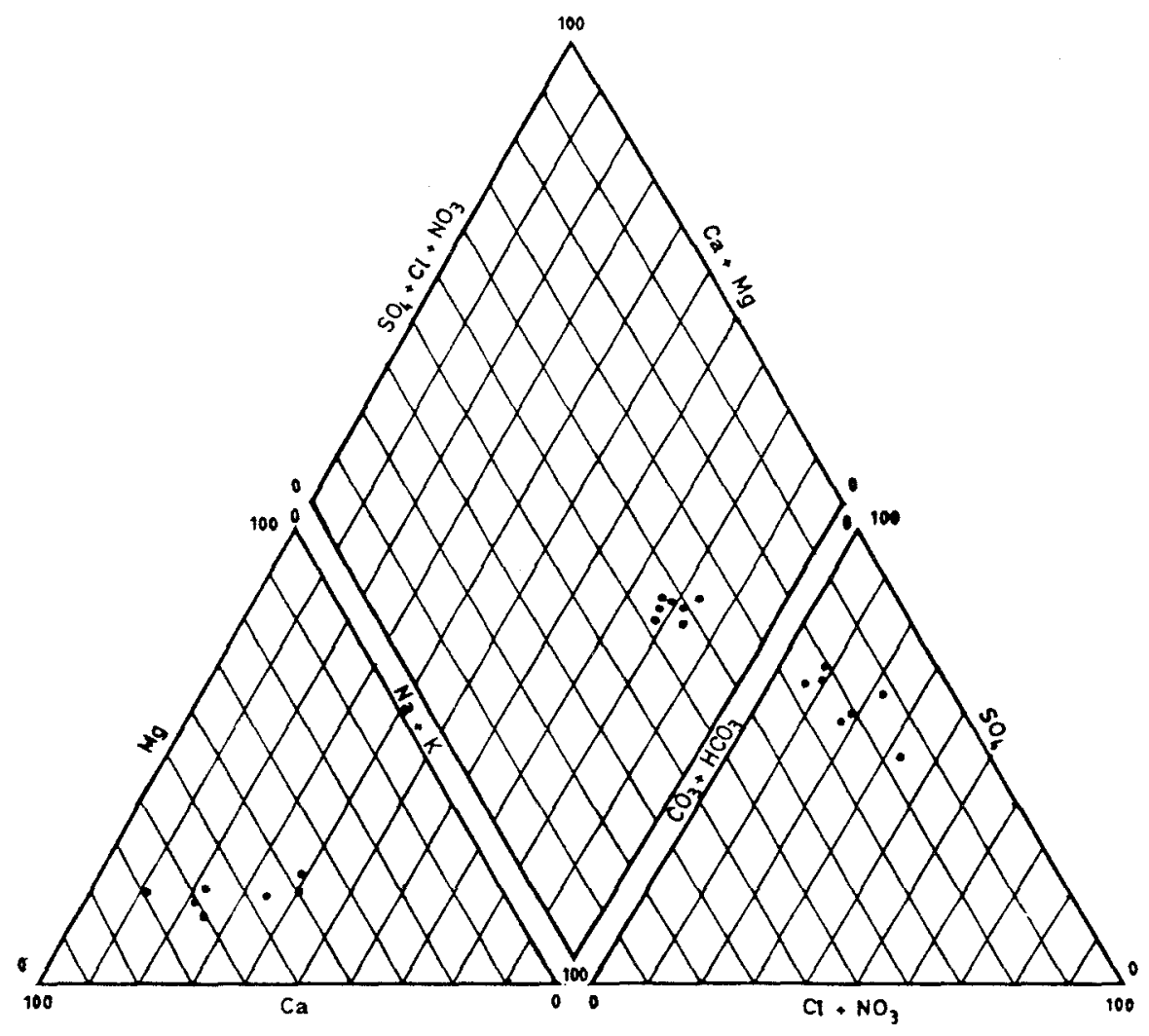

Fig. 1. Representación de las muestras en el diagrama de Piper.

cia a las sales, o en todo caso, dada su naturaleza física (aguas termales), puede aplicarse eficazmente en tratamientos terapéuticos.

Entre los cationes, el $\mathrm{Ca}^{++}$es el más abundante en el total de muestras, siendo en el manantial 25345009, situado al NE del Cenajo, donde tiene mayor importancia (300 mg/l), como consecuencia del potente tramo de calizas jurásicas que atraviesan sus aguas; el $\mathrm{Na}^{+}$mantiene unos valores próximos a los del $\mathrm{Ca}^{++}$en Azaraque, punto en el que oscila entre 230 y $297 \mathrm{mg} / \mathrm{l}$. El contenido en magnesio, pese a no ser dominante respecto a los dos tipos de cationes anteriores, es bastante importante: $162 \mathrm{mg} / \mathrm{l}$ en Azaraque, $95 \mathrm{mg} / \mathrm{l}$ en La Pestosa y $89 \mathrm{mg} / \mathrm{l}$ en Sta. Quiteria son cantidades bastante apreciables.

Resultado de esta distribución de iones son las facies que caracterizan al agua. Asi, la mayoria de las muestras son de «facies cloruro-sulfatada 
y sulfatada-cálcica», hallándose relacionadas con la presencia de arcillas y margas yesíferas. La facies más diversificada corresponde a las aguas de Azaraque, que pueden catalogarse de "cloruro-sulfatadas-sódicasmagnésicas».

Por sus componentes químicos, y de acuerdo con la Reglamentación Técnico-sanitaria de junio de 1982, éstas no reúnen en ningún caso las condiciones mínimas para su consumo como aguas potables. Son, en cambio, tolerables para el riego y adecuadas para usos con fines medicinales.

\section{LOS BALNEARIOS EN LA COMARCA DE HELLINN-TOBARRA}

En el I Congreso de Historia de Albacete ya se describieron, en un interesante artículo ${ }^{15}$ los baños del Azaraque como primera aportación al tema. Lamentablemente la sugerencia no fue atendida en posteriores encuentros ${ }^{16}$ y careció la buena idea de una auténtica continuidad.

Por el contrario, existen ciertas citas, de inestimable valor, en los diccionarios geográficos y enciclopédicos desde el siglo XVIII y XIX que nos informan de las propiedades curativas de las aguas termales y de la aceptación que alcanzaban entre los naturales del territorio.

Por ello, las encuestas y la tradición oral constituyen el otro basamento fundamental para indagar en la hidroterapia y las aguas salutíferas en conjunto. Todavía hoy en día, los ancianos de las aldeas y de las localidades de la comarca recuerdan las aplicaciones y apariciones milagrosas vinculadas a los manantiales.

La visión del tema se complementa con la prospección arqueológica para determinar qué culturas se instalaron previamente en las inmedia-

\footnotetext{
${ }^{15}$ Lillo Carpio, M. J. y Selva Iniesta, A., "Consideraciones sobre los antiguos baños del Azaraque", Congreso de Historia de Albacete. Vol. I: Arqueologia y Prehistoria. Albacete 1983, págs. 377-387. Albacete 1984.

${ }^{16}$ No hay ninguna aportación concreta y específica en el / Congreso de Historia de Castilla-La Mancha, celebrado en Ciudad Real en 1985. No se trata el tema, por ejemplo, en el I/ Seminario de Geografía reunido en Albacete (1982) ni en el I/l (1984). La gran obra de Sanchez Sanchez, J., Geografía de Albacete (1982), tampoco recoge el tema de los balnearios o del termalismo. La revista Al-Basit, del mismo modo, carece de una sola publicación en esa dirección.
} 


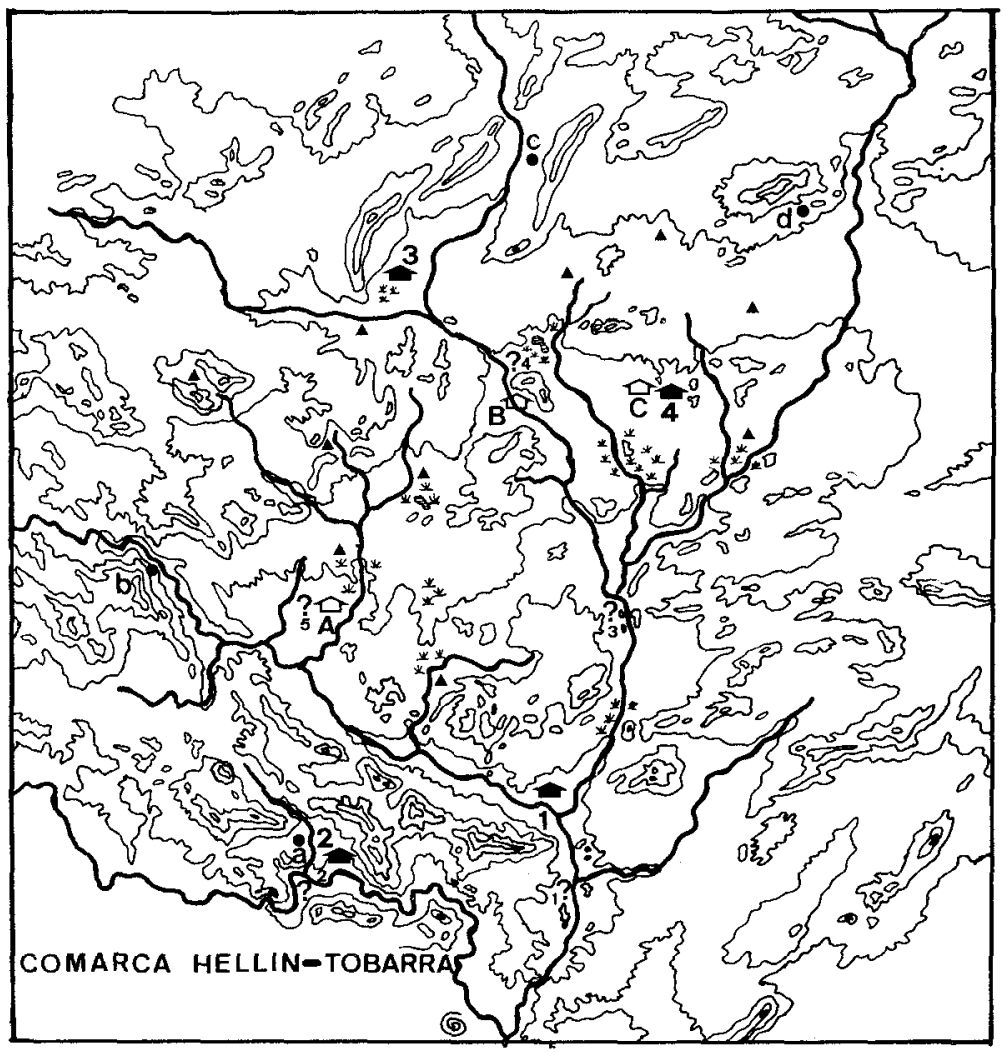

Balnearios: 1 = Azaraque (Agramón); $2=$ Cenajo; $3=$ La Pestosa (Tobarra); 4 = Santa Quiteria.

$\triangle$ Termas según la toponimia, las fuentes escritas o la arqueología: $A=B a-$ ños de la Reina de Isso; $B$ = de Santa Victoria en el Castellar de Sierra (Tobarra); $C=$ de la villa romana de Santa Quiteria (Tobarra).

- Fuentes salutiferas (no termales necesariamente) citadas por las fuentes o la tradición oral: $a=$ El Cenajo; $b=$ La Vicaria (Isso, Hellín); $c=$ El Puerto (Tobarra); $d=$ El Madroño (Albatana-Ontur).

- Otras fuentes (no minerales necesariamente) de gran importancia local por su caudal, por su vinculación a yacimientos arqueológicos o por la leyendas relacionadas con ellas.

? Encantadas: $1=$ Camarillas; $2=$ El Cenajo; $3=$ Tolmo de Minateda; $4=$ Catellar de Sierra (Tobarra); $5=$ Isso. 
ciones de los manantiales y en qué aspectos explotaron sus aguas o sus propiedades médicas ${ }^{17}$.

Antes de introducirnos en el recorrido por las fuentes y la tradición oral, hay que hacer una observación. De los balnearios y fuentes que citamos, sólo dos son termales en sentido estricto: El Cenajo y Azaraque. La Pestosa y Santa Quiteria son aguas minerales pero prácticamente a temperatura ambiente en su nacimiento.

\subsection{Fuentes e historia de la investigación de los balnearios}

\section{A) Balneario de Azaraque (Agramón-Hellín)}

Las relaciones Topográficas de Felipe $\|{ }^{18}$ correspondientes a la villa de Hellín, aunque mencionan algunas fuentes de Agramón y de Minateda, nada indican acerca de este nacimiento termal. Con casi plena seguridad se puede afirmar que en el siglo XVı no se utilizaba el manantial con fines terapéuticos sino, en el mejor de los casos, como agua de riego. La prospección arqueológica no ha detectado yacimientos de importancia en el valle del Mundo tras el poblamiento del Bronce Medio y Final. Muy posiblemente se produjo un abandono del río Mundo en algunos sectores que perduró hasta el siglo XVIII, cuando parece que se ponen en regadío amplias huertas y se construyen canalizaciones, acequias y acueductos de envergadura ${ }^{19}$.

Es precisamente en el año 1746 cuando CERDÁN ${ }^{20}$ analiza con bastante detalle los baños del Azaraque e indica qué parte del agua se utilizaba para riego. Describe las aguas del manantial como transparentes y precisa que desprenden un característico olor a azufre. Señala además que

17 Sirva como ejemplo próximo en el espacio el artículo de SÁnchez Gomez, J. L., «Panorama arqueológico de Socovos", I Congreso de Historia de Albacete. Vol. I: Arqueología y Prehistoria. Albacete 1983. En la página 349 se describe el yacimiento de Los Bañuelos que el autor considera como "restos de baños termales", con hipocausto de arcadas de ladrillos, base de piscinas y canalizaciones cerámicas.

is Fueron redactadas en Hellín en el año 1576.

${ }^{19}$ A lo largo de la ribera septentrional del rio Mundo, entre las localidades de Isso y de Agramón, se detectan infinidad de obras y estructuras complejas: acequias, presas, acueductos, pozos, captaciones de agua, canalizaciones,... etc., que bien merecerian un detallado estudio por parte de especialistas. Destaca entre todas esas obras la llamada «Alcantarilla», extraordinario ejemplo de la arquitectura civil, probablemente del xvIII.

${ }^{20}$ CERDÁN. Disertación físico-médica hidráulico analitica sobre los baños del Azaraque, sitos en el término de la villa de Hellín, sus propiedades medicinales y métodos de usarse. Valencia 1746 . 
el calor del líquido y la composición de sales disueltas en él, permitía cocer el cáñamo en apenas dos días, cuando, a tenor de los datos que proporciona, se precisaban en otras balsas y con otras aguas, unas veinte jornadas.

También describe Cerdán el ritual para proceder a la cura: el paciente debía estar «bien evacuado», levantarse al salir el sol, beber en ayunas el agua de la fuente, pasear un rato por el entorno arbolado,... etc. Finalmente se procedia a un baño de una hora dentro del estanque que retenia las aguas. Tras la inmersión, el paciente debia desayunar alimentos ricos en calorias (chocolate y caldos) para, estando bien abrigado, sudar.

Concluye Cerdán con una alabanza a los baños del Azaraque y estima que sus aguas son más beneficiosas y útiles que las de Archena o Fortuna en Murcia.

Pero una década después, Gómez DE BEDoya ${ }^{21}$ narra las deficiencias que aquejaban a las instalaciones del Azaraque, donde no había ningún tipo de habitación o albergue para los visitantes que a ellas acudían. Las enfermedades que curaban las aguas del Azaraque según Bedoya eran: tercianas, cuartanas, obstrucciones, ictericias, ciáticas, reumatismos, dolores nefríticos, malestar en la vejiga urinaria, estreñimientos,... etc.

En 1770 , NiPHo ${ }^{22}$ relata la presencia de una balsa de considerables dimensiones, donde hay "aguas muy cristalinas" aunque exhalan olor a azufre. Indica que las aguas depositan «un lodo negro y untoso". Insiste en la rapidez con la que se cuece el cáñamo sumergido en las balsas del Azaraque. Lo más interesante es que ya menciona la construcción de hospedajes para los enfermos y visitantes del balneario, para «la multitud de personas de uno y otro sexo que en primavera y otoño concurren a tomar las aguas de esta fuente por medicina y baños». Sin embargo, precisa que el número de habitaciones no era suficiente para acoger a todos los dolientes y que éstos debian solicitar posada en las casas vecinas o incluso acampar en las inmediaciones del paraje.

Nipho aporta otro dato fundamental: las propiedades de las aguas del Azaraque fueron descubiertas por el médico titular de Hellín, el señor Cerdán, en el año 1745. Quizás sea ésa la fecha del inicio de los baños ya que, como indicábamos al principio, amplios sectores del río Mundo no recibieron la influencia humana hasta el siglo xvill. Según Nipho, la

\footnotetext{
${ }^{21}$ Gomez de Bedoya, P., Historia Universal de las fuentes medicinales de España. Santiago de Compostela 1765 (t. II, pág. 289).

${ }^{22}$ NiPHo, F. M., Relación del Corregimiento de Hellín, en el reyno de Murcia. Madrid 1770 , págs. 293-295.
} 
fama del manantial se había difundido con extraordinaria rapidez por la región.

Concluye elaborando un catálogo de enfermedades que sanan con la inmersión en el Azaraque, pero inspirándose en las obras de Cerdán y Bedoya. No obstante, añade que son perjudiciales para los écticos, los tísicos y los atrópicos así como para los «demasiado extenuados».

Años después ESPINALT ${ }^{23}$ sólo dirá que en Hellín hay multitud de fuentes que «hermosean» la ciudad y que son «dulces y delicadas» y con «abundantes sales que se cogen». Pero omite cualquier referencia directa al Azaraque. También TOMÁs LóPEz ${ }^{24}$ hace una mención marginal de él y sólo apunta que el lugar era muy visitado por forasteros y naturales.

A principios del siglo XIX, Miñano ${ }^{25}$ recupera, en la voz de Agramón, el tema de los baños del Azaraque e indica que sus aguas estaban compuestas por "fosfate, calipso y azufre». Recuerda que aquellas aguas «minerales thermales" están "muy concurridas» gracias a las mejoras introducidas por sus dueños en las instalaciones. Sin embargo, Miñano en el mismo Diccionario recabó información complementaria de un erudito de Hellín, D. José Rodríguez Carcelén, quien, más enterado sobre el terreno de las circunstancias, describe las habitaciones de los baños de Azaraque como indignas, seguramente refiriéndose a la penuria de medios higiénicos y de hostelería: “las habitaciones son pocas, carísimas e indecentes, tanto que en el invierno suelen servir de aprisco para el ganado". Mejor descripción de la miseria era imposible. Así, el Azaraque le sería muy díficil poder competir en el futuro con los baños de Archena y de Fortuna. El abandono y la carencia de iniciativas por parte de los sucesivos dueños del Azaraque, según el Sr. Rodríguez Carcelén, motivaron la posterior ruina de los baños y la reconversión en simple agua de riego del nacimiento.

A mediados del XIX, MADOz ${ }^{26}$ insistirá en las penurias y miserias de los baños del Azaraque y aún añadirá nuevas deficiencias, a las ya detectadas por Miñano. Repetirá la incomodidad de las estancias y añadirá el hecho de que los visitantes y bañistas debian llevar consigo hasta lo más insignificante para poder desarrollar las actividades más cotidianas y poder satisfacer la más mínima necesidad. Por otra parte denuncia que

\footnotetext{
${ }^{23}$ Espinalt, B., Atlante Español. Madrid 1778-1795 (Voz: Villa de Hellín), págs. 191-203.

24 TOMÁs LoPEz, Diccionario Geográfico Madrid 1786-89 (Voz: Ellín).

25 Miñano, S., Diccionario geográfico-estadístico de España y Portugal. Madrid 1986-29 (Voz: Agramón y Hellín), págs. 27-28 y 340-345.

${ }^{26}$ Madoz, P., Diccionario geográfico-estadístico-histórico de España y sus posesiones de Ultramar. Madrid 1845-50 (Voz: Hellin).
} 
el balneario se encuentra próximo a cultivos de arroz en cuyas charcas se desarrolla el paludismo y carece de un sólo médico que atienda y oriente a los pacientes y clientes potenciales.

Como dato nuevo respecto a los anteriores informantes, Madoz sabe que los viajeros que acuden al Azaraque proceden de numerosas localidades de La Mancha. Posiblemente su fama no se extendía más allá.

\section{B) Balneario de El Cenajo (Hellín)}

Los textos geográficos apenas si mencionan el balneario de El Cenajo. La fuente es citada ya en las Relaciones Topográficas de Felipe II pero nada se indica en ellas acerca de su posible aplicación en la medicina. Sin duda, el valle del Segura estaba tan poco explotado como el valle del Mundo en el siglo xvi en la comarca de Hellín-Tobarra.

Hay que esperar hasta mediados del siglo XIX para que $\operatorname{MADOZ}^{27}$ lo reseñe pero advirtiendo que su estado de abandono era muy lamentable y que recordaba las penurias del balneario del Azaraque.

\section{C) Balneario de La Pestosa (Tobarra)}

Tampoco es citado en ningún texto. La alusión de MADOZ ${ }^{28}$ a unos baños parece indicar los de Santa Quiteria. La ausencia de menciones nos anima a suponer que estos baños de La Pestosa fueron construidos y organizados después de mediados del siglo XIX.

Donde sí aparecen citados es en la Enciclopedia Universal llustrada Europeo-Americana (España Calpe), en la voz Tobarra (Vol. 62). Publicada en 1928, ya hacia tres años que, según la tradición oral, los baños estaban clausurados por falta de medidas higiénicas y de servicios adecuados. Sin embargo indica las fechas de la temporada de baños y las aplicaciones medicinales de sus aguas.

\section{D) Balneario de Santa Quiteria (Tobarra)}

Ya en siglo XVI, las Relaciones Topográficas de Felipe II muestran especial interés por las aguas de este manantial. Nada indican acerca del nacimiento de La Pestosa pero sí describen con sumo detalle los de la aldea de Santa Quiteria:

\footnotetext{
27 Madoz, P., Op. Cit. (Voz: Hellín), págs. 163 y 165.

${ }_{28}$ Madoz, P., Op. Cit. (Voz: Tobarra), pág. 767.
} 
«Y ansi mismo por el mal de rrabia, esta Villa tiene por particular abogada a la bien abenturada Santa Quiteria, a cuya ynbocacion tienen hecha una iglesia a legua y media desta Villa, donde ay una fuente, que se diçe la fuensanta, con cuya agua sanan muchas beçes los que están mordidos de canes y animales rrabiosos, y de otras henfermedades, y se han bisto munchos milagros en la dicha ermita, por ynterçision de la Bienabenturada Santa, en personas que an estado mordidas de animales rrabiosos, y aún en personas que padeçian el dicho mal de rrabia».

El texto, sin duda, es muy importante pues es la primera evidencia documental del recurso de aguas milagrosas en la comarca. El nacimiento del agua ya estaba cristianizado por la construcción de una ermita y se hallaba bajo el control del clero católico.

A finales del XVIII EsPINALT ${ }^{29}$ recoge de nuevo el tema de las aguas de Santa Quiteria y señala que hay alli estructuras de piedra labrada. Entre las propiedades de los baños resalta la erradicación de la sarna, de la lepra, de las obstrucciones y de los dolores histéricos.

Pero es más interesante la aportación de TOMÁs LOPEZ ${ }^{30}$ por los mismos años. Según el autor, en Santa Quiteria habia una ermita «muy decente» y una casa con todos los utensilios necesarios para «los devotos» que acudian en romería al manantial, bien a tomar los baños por inmersión, bien a beber en recipientes. Las aguas de la fuente servian para curar la sarna, la lepra, las obstrucciones, la hipocondria, los dolores histéricos y los gálicos,... etc.

A mediados del xIX, MADOZ ${ }^{31}$ cita otra vez el balneario de Santa Quiteria. Añade que cura los herpes. Alaba las habitaciones de la hospederia y lo ameno de un jardín que allí era cuidado.

\section{E) Otros balnearios y fuentes salutíferas}

Los textos nos proporcionan una serie relativamente amplia de fuentes salutiferas o con especiales propiedades.

Así, TOMÁs LóPEZ ${ }^{32}$ menciona a fines del XVIII una fuente de agua fría que alcanzó excelente reputación entre los naturales de la región. Se encontraba en el paraje de El Puerto, en Tobarra, y era llamada la Fuente del Agua Buena, "muy cristalina, dulce, sutil y delgada". Su aplicación

\footnotetext{
${ }^{29}$ Espinalt, B., Op. Cit. Voz: Tobarra), págs. 143-148.

30 TOMÁs López, Op. Cit. (Voz: Tobarra), págs. 215-217.

${ }^{31}$ Madoz, P., Op. Cit. (Voz: Tobarra), pág. 767.

32 ToMÁs López, Op. Cit. (Voz: Tobarra), pág. 216.
} 
fundamental era remediar el mal de orina, las piedras del riñón y las indigestiones.

El mismo autor ${ }^{33}$ recuerda otra fuente situada en el macizo del Madroño, entre Albatana y Ontur, entre cuyas virtudes estaba la de «enflaquecer a las personas mui obesas y cargadas de carne».

MADOZ ${ }^{34}$, a mediados del XIX se hará eco de atro pequeño manantial en el caserio de la Vicaria (¿Peña Lavada en el río Mundo?) también de aguas frías. Se aplicaba con éxito para curar las erupciones cutáneas, los reumas y «otras dolencias».

Algunos autores añaden además una serie de topónimos o describen ciertas ruinas arqueológicas que, acaso, pudieron ser viejas termas romanas. Así, BLANCH E ILLA ${ }^{35}$ habla de unos supuestos baños romanos en Tobarra o en el Castellar de Sierra y que dice que se denominaban de Santa Victoria, en recuero de una hipotética mártir cristiana que hubo allí ${ }^{36}$. En Isso, Lozano ${ }^{37}$ menciona «los baños de la reina» en los que se distinguian ciertas estancias y conductos subterráneos.

\subsection{La tradición oral y los balnearios}

\section{A) Baineario del Azaraque (Agramón-Hellin) ${ }^{38}$}

Según los naturales de Agramón a los baños del Azaraque se les llamaba los Baños de la Marquesa, acaso en un intento de crear un ambiente mágico en torno a los poderes de sus aguas.

Para la mentalidad popular las aguas sanaban las "granujadas" (conjunto de granos) cuando los hombres y mujeres se bañaban en la balsa.

Se afirma también que el agua del Azaraque no se puede embotellar porque lo que contiene en sales hace "explotar" los envases.

Cuentan los vecinos que eran muy frecuentes las visitas de gentes del Altiplano de Jumilla-Yecla, de la sierra de Albacete y de "otros sitios» dentro del ámbito regional.

${ }^{33}$ TOMÁs LópEZ, Op. Cit. (Voz: Tobarra), pág. 217.

${ }^{34}$ Madoz, P., Op. Cit. (Voz: Hellin), pág. 165.

${ }^{35}$ Blanch E Illá, N., Crónica de la provincia de Albacete. Madrid 1866, pág. 15.

${ }^{36}$ Iniesta Villanueva, J. y Jordan Montes, J., Leyendas y creencias en la comarca de Hellin-Tobarra (En prensa).

${ }^{37}$ Lozano, J., Bastitania y Contestania del Reino de Murcia. 1794, pág. 36.

${ }^{38}$ La tradición oral acerca de los baños de Azaraque ya fue recogida por sus primeros investigadores, Lillo Carpio y Selva INiESTA (Cf. Nota 1). Nosotros hemos ampliado el número de entrevistas tratando de perfilar algunos detalles al respecto. 
Aguas termales y mineromedicinales en el valle bajo del río Mundo ...

Recuerdan que hubo unas cuatro habitaciones para alquilar con chimenea y dormitorio para las familias que deseaban descansar unos dias en el balneario.

Se dice igualmente que el ganado también se beneficiaba de las propiedades curativas de las aguas termales.

Además de las habitaciones de alquiler para pernoctar, en la balsa o estanque había otras tres estancias (hoy sumergidas y de las que sólo son visibles los cimientos bajo las aguas) para el baño directo.

Según los primeros investigadores del Azaraque, los baños de la hacienda fueron cerrados hacia el año 1963. La razón fundamental fue la tremenda competencia que sufrian del balneario de Archena y de Fortuna, mejor equipados médicamente y con mayores servicios hidroterápicos.

\section{B) Balneario de El Cenajo ${ }^{39}$}

Se les llamó también los Baños de la Reina, tal vez por las razones ya expuestas en el Azaraque. Todo lo misterioso que ha dejado de usarse y de conocerse en su mecanismo lógico y cotidiano, adquiere pronto un aura de magia y antigüedad. Hay también una vieja leyenda que habla de la aparición de una «encantada» en el lugar. En otros trabajos ya hemos insistido en la posible identificación de las encantadas con las ninfas romanas.

Las aplicaciones hidroterápicas, según los naturales, remediaban la sarna, los granos y las úlceras de la piel. Pero el dato más significativo fue cuando se nos indicó que los mineros de Las Minas que extraían el azufre en la confluencia del Mundo con el Segura, solían acudir al menos una vez por semana para bañárse en las aguas termales de El Cenajo. Lo hacían para aliviar los dolores y escozores provocados por la manipulación del azufre.

Otros visitantes procedian de las provincias de Albacete o de la región de Murcia.

Según se nos mostró hubo hasta seis habitaciones con chimenea para albergar a las familias que acudían desde lejos. Si bien no era extraño que la mayoría durmiera a la intemperie. Decenas de carros y carretas

\footnotetext{
${ }^{39}$ Una información bastante detallada sobre la evolución de los baños y acerca de la situación de algunos elementos y características del conjunto, fue proporcionada por el Sr. Pedro García, nieto de los antiguos dueños del viejo balneario del Cenajo, y por el Sr. Manuel Benitez. A ambos les expresamos nuestro agradecimiento por la valiosa información amablemente ofrecida.
} 
se reunian los fines de semana en el paraje y decenas de mulos transportaban a los bañistas desde sus domicilios hasta el pequeño balneario.

Los nacidos en el caserío nos informaron que el balneario dejó de funcionar, con un mínimo de organización, hacia el año 1945.

Hoy en dia aún se distinguen algunas casas-cueva en los cingles próximos al balneario. Los ancianos que entrevistamos nos precisaron que en principio habian sido chozas o abrigos para el ganado o para guardar la paja o el alimento de las bestias. Más tarde, cuando comenzó a construirse el pantano de Cenajo, tras la Guerra Civil, aquellas oquedades fueron ampliadas y usadas como habitaciones por los obreros. Cerca, estuvo también un viejo poblado de mineros extractores de azufre, junto al cauce del Segura, en un meandro. Aprovecharon igualmente casas-cueva.

Tras la culminación de la presa del Cenajo, el abandono de las minas de azufre y a causa del alejamiento de aquel paraje de las ciudades o núcleos de población más atractivos (Hellín e Isso) y del éxodo rural, aquellos humildes baños quedaron pronto en el olvido y en la más absoluta ruina.

\section{C) Balneario de La Pestosa ${ }^{40}$}

En su origen el nombre del balneario fue Fuente de la Apestosa, por el caracteristico olor que desprendian sus aguas.

Los baños eran indicados para combatir el reumatismo, la ciática y todas las enfermedades propias de la piel. No se trataba de auténticos baños termales sino de aguas medicinales. En efecto, el agua extraída de un pozo, mediante un animal que giraba uncido a un malacate, era inmediatamente calentada en grandes calderas con leña como combustible. Más tarde se utilizó el carbón.

Los visitantes acudian desde Almansa, Ontur, Hellín y en general de pueblos de la provincia de Albacete. Se constata la visita de algún militar con destino en Melilla.

La distribución del enorme conjunto, sin duda el mayor de toda la comarca, era la siguiente: en la planta baja del edificio principal en forma de «n» se instalaron las dependencias del médico y el recibidor (lateral

\footnotetext{
${ }^{40}$ La tradición oral fue obtenida de una entrevista efectuada a la familia que en la actualidad custodia el caserío de Santa Quiteria y que son propietarios de la finca. Tuvimos el placer de hablar con la señora Juana García Ochoa (75 años) y con el señor Miguel Garcia Garcia (70 años). A ambos les quedamos muy agradecidos por la hospitalidad y el lujo de detalles que nos ofrecieron.
} 
derecho) así como el casino y el comedor (lateral izquierdo). También en la planta baja funcionaban doce salas de baño. En la primera planta existían hasta veinte y cuatro habitaciones para hospedaje. Esto conferia a los baños de la Apestosa una capacidad de albergue muy superior a la del resto de la región. En la visita a las actuales ruinas creímos poder distinguir un anexo edificado en la parte occidental del conjunto que bien pudieron ser nuevas habitaciones, añadidas cuando se incrementó la demanda. Su número alcanza la quincena. En la parte septentrional del edificio, adosado a él, hubo un patio semicubierto y otras estancias asignadas a las bestias de carga y transporte. Contamos hasta una cincuentena de pesebres o comederos lo que ofrece una ligera idea de la capacidad de la obra y de las instalaciones.

El balneario surgió por casualidad según los informantes. En un principio el agua obtenida de un pozo recién abierto iba a ser destinada al riego. Pero al percatarse los dueños de la riqueza que contenía el líquido y de que era susceptible su explotación medicinal, optaron por la fundación de los baños. Era el año de 1905 aproximadamente. El cierre se produjo hacia el año 1925 cuando, según se nos relató, prosperaron ciertas denuncias que el dueño del balneario de la laguna de Pétrola había presentado con anterioridad. El señor Yáñez, médico y concejal por aquel entonces de Albacete y dueño del mencionado balneario de Pétrola, había visto siempre con preccupación la fuerte competencia que su negocio recibía a causa de los baños de Tobarra (seguimos siempre los datos proporcionados por la tradición oral). A su vez, los dueños de la fuente de La Apestosa no pudieron remediar las deficiencias detectadas ya que carecían de capital suficiente para reconvertir los baños y para dotarles de condiciones idóneas. Otras versiones eluden hablar de rivalidades entre balnearios e inciden más en desavenencias entre los herederos.

El número de empleados en el balneario fue importante. Al "bañero» con sus dos ayudantes, había que añadir la cocinera, el encargado del casino y de la tienda con todo su personal correspondiente, a los que cuidaban los animales, el médico,... etc.

El paraje era utilizado también ocasionalmente con motivo de fiestas y bailes de Tobarra lo que le otorgaba una vistosidad nueva. Recuérdese la presencia de un casino en el mismo edificio del balneario. Si a todo ello añadimos una importante afluencia de visitantes y usuarios que acampaban en las inmediaciones del manantial porque su condición económica no les permitía costearse una habitación en el balneario, observaremos un centro abigarrado pleno de vida. El ir y venir de carros y tartanas, el transporte de viveres y productos, los paseos y las charlas, conformaban un conjunto de gran colorido. 
Según se nos relató, el balneario tuvo una efímera segunda apertura al comienzo de la II República, cuando se trató de asignarle una utilidad pública y popular, dirigiendo la explotación el propio Ayuntamiento. La iniciativa concluyó pronto: desde 1932 a 1935.

La temporada se iniciaba, según los años, a fines de mayo o mejor a principios de junio y concluía hacia mediados de septiembre o finales, cuando ya el frío comienza en esta tierra de clima mediterráneo continentalizado. Cerca se encontraba la fuente de la Laguna, aprovechada por aquellas personas carentes de recursos para hospedarse. La toponimia nos revela que en aquel lugar, en tiempos, hubo al menos un almarjal. Las propiedades del agua de dicha fuente eran similares a las del pozo del balneario. La única diferencia es que no se utilizaban las bañeras de granito artificial o de mármol para tomar los baños.

\section{D) Balneario de Santa Quiteria ${ }^{41}$}

La tradición oral relata que en el paraje donde se encuentra la fuente medicinal se apareció la Virgen a un pastor. El cabrero observó que cuando acudia con su hatajo a abrevar los animales se le espantaban de forma irremediable. Se le ocurrió entonces arrojar una piedra al fondo de la fuente. Cuando se acercó para verificar si había impactado en el ser que asustaba a su ganado, se percató de que en realidad le habia roto el dedo meñique a una imagen de una Virgen ${ }^{42}$. Casi con certeza podemos aventurar que la Virgen sustituyó al recuerdo de alguna deidad acuática de época romana o a alguna ninfa.

Las aguas de la fuente servían para sanar todas las enfermedades relacionadas con la piel. La tradición del siglo xvi por la cual esta Virgen era abogada contra la rabia, aún se intuye ya que la imagen suya que hoy se conserva, presenta a sus pies un perro.

Los residentes en el cortijo afirmaban que el lugar era muy visitado por gentes del Altiplano de Jumilla-Yecla, de Pozo Cañada, de Albacete,... etc.

\footnotetext{
${ }^{41}$ Para más detalles sobre el carácter milagroso de la imagen y el posible simbolismo de la narración, ver la obra citada en la nota 37.

${ }_{42}$ Para obtener la información oral de este balneario recibimos la atenta y amable colaboración del señor don José Emilio Ramona, director de la Casa de Cultura de Tobarra, quien nos presentó a la señora Simona Martínez Alcañiz de 73 años, natural de la ciudad e hija de los antiguos propietarios del balneario. Igualmente entablamos conversación con la señora Candelaria Onrrubia Córcoles de 75 años, que fue usuaria de los baños y que tuvo el interesante oficio de ordinario hasta los setenta años de edad. A todos ellos les expresamos desde aquí nuestro reconocimiento y gratitud por su entrega y amabilidad.
} 
Según los informantes hubo alli unos tres cuartos destinados al baño, además de habitaciones para posada.

El final del balneario fue datado por las personas entrevistadas unos años antes de la Guerra Civil, hacia 1925 aproximadamente. Según nos indicaron, los archivos y la antigua imagen de la Virgen fueron precisamente destruidos e incendiados durante la contienda. En la actualidad la vieja ermita que acompañaba a las aguas salutíferas está prácticamente en ruinas y tan sólo se utiliza como garaje y almacén de productos agropecuarios.

\subsection{La Arqueologia ${ }^{43}$ y los balnearios}

\section{A) Balneario del Azaraque}

En la actualidad el balneario se mantiene con vida pero reconvertido en una hacienda. De las estancias para baños quedan los cimientos sumergidos en el estanque construido para almacenar el agua del manantial cuando no se utiliza en el riego de la huerta.

No obstante, en una inspección realizada en el caserio, en la parte más próxima al caudal del río Mundo, observamos una estructura cubierta cuyo basamento estaba contruido con grandes sillares perfectamente labrados y ensamblados entre sí. Esta parte inferior nos atreveriamos a incluirla dentro del catálogo monumental romano. Se trata del zócalo de lo que en tiempos se llamó "Baños de la Marquesa». Muy probablemente la mitificación de dicha estancia revele un origen muy antiguo.

Aunque cerca hubo un asentamiento eneolítico, en las colinas suaves situada el SE de la finca, es la cerámica romana la que más nos interesa. Las prospección ${ }^{44}$ fue realizada en las tierras de labor y jardines de la casa del Azaraque y proporcionó los siguientes datos: cerámica gris romana y sigillatas hispánicas (formas 24, 25 y 27 Drag.). La escasez del material estuvo causada por el tremendo desmonte realizado para crear bancales y jardines en las inmediaciones de la casa del Azaraque. Las plantaciones y la arboleda natural del soto dificultaron enormemente la prospección. Pero no cabe duda de que aquel paraje fue ocupado durante la romanización desde mediados del siglo I d. C.

\footnotetext{
${ }^{43}$ Los datos arqueológicos sobre localización de yacimientos y asentamientos prehistóricos y romanos proceden de nuestra tesis de licenciatura El poblamiento prehistórico en la comarca de Hellín-Tobarra. Murcia 1981 (Depositada en el Instituto de Estudios Albacetenses).

${ }^{44}$ Materiales recogidos en nuestras prospecciones y en las del amigo y colega GaRcia BLÁZqUEZ, L. A.
} 


\section{B) Balneario de El Cenajo}

Hoy en día el viejo balneario es un caserío en proceso casi irreversible de ruina. Sirve únicamente como almacén. En diversos anexos se aprecian estancias que fueron destinadas a corrales de animales o para carros. En los cingles superiores se instalaron antiguos graneros luego reconvertidos en viviendas para mineros y obreros de la presa del Cenajo.

De las instalaciones de baños en sí, no restan más que unas lajas de roca, ocho en total, que conforman un rectángulo incompleto adosado a un escalón pétreo, a cuyo pie nace el manantial. Sus dimensiones son de $400 \mathrm{cms}$ de longitud por 200 de anchura. Ese espacio cerrado, la antigua sala de baño, carece de suelo y las algas y los peces pululan en el liquido. Hubo en su tiempo una estructura o cobertizo que protegía a los bañistas. Hoy ha desaparecido totalmente y apenas si se aprecia una muesca en una de las lajas, indicando por donde se accedia al interior del baño termal.

Respecto a la presencia de culturas anteriores, el material que ofrece la prospección ${ }^{45}$ es de lo más sugerente y podemos afirmar que hubo una continuidad de ocupación y utilización del paraje y de las aguas desde el Eneolítico hasta el dominio romano, inclusive.

En las proximidades de la fuente de agua caliente detectamos varias estaciones eneolíticas y del Bronce Inicial. Una de ellas se instaló en un cerro amesetado, de reducidas dimensiones, situado hacia el W, en el arroyuelo del Cenajo. Otra parece ser que ocupó las repisas de los farallones blancos también levantados hacia el $W$, en la orilla del río Segura. La última se sitúa hacia el $\mathrm{E}$ en una diminuta muelecita rodeada por una barranca honda.

Del Bronce Medio y Final se aprecian algunas piezas cerámicas con formas de platos de labios muy exvasados.

Del mundo ibérico el material es muy abundante. Los naturales del entorno recuerdan el topónimo los Castillicos, correspondiente a la cota 515 que en forma de meseta se elevó en su tiempo al $W$ de la fuente. Hoy en día dicha cima está arrasada por explotaciones mineras; pero sin duda albergó un asentamiento del bronce o ibérico. El material hallado en la ribera, junto al viejo balneario puede corresponder a una necrópolis de incineración.

En las cerámicas áticas de Barniz Negro destacan dos piezas:

45 Prospecciones realizadas por el equipo en 1982, en 1989 y en 1992. 
Aguas termales y mineromedicinales en el valle bajo del río Mundo ...

- Fragmento de pie de un kylix de labio cóncavo y moldura interna tipo Cástulo cup de Shefton, fechable en la segunda mitad del siglo v a. C. (440-420 aprox.).

- Posible fragmento de un plato ático, acaso del siglo Iv. No se pueden deducir más datos.

La cerámica ibérica está ampliamente representada por una serie de platos (fechados hacia finales del v o principios del Iv a. C.) y vasijas globulares.

En cuanto a las cerámicas decoradas todas ellas corresponden a fases muy antiguas con decoración geométrica simple de bandas y líneas, posiblemente de finales del $\vee$ y principios del IV. Hay algún motivo de zigzag y de círculos concéntricos. Destacan fragmentos de platos tipo cuenco. Igualmente es digno de reseñar un posible trozo de cerámica ibérica de barniz rojo, tipo $D$, datable en el siglo IV.

La cerámica gris ibérica tosca es muy abundante. Hay ollitas, tapaderas, cuencos y un fragmento de oinokoe. Todo ello puede revelar que en el lugar del hallazgo se realizaron los rituales funerarios. En efecto, entre ese material se encontró también un fragmento de falcata.

Se recogieron además asas de ánforas ibéricas y un cuello de ungüentario ibérico, acasc del IV.

De época romana son cuellos y basamentos de ánforas, gruesos labios de dolia de aceite y cereal y bordes y fondos de morteros romanos.

Respecto a las sigillatas el catálogo es arnplio: sudgálicas, hispánicas, Claras A, Claras C y, acaso, algún ejemplar de Clara D. El conjunto abarcaría desde el segundo cuarto del siglo । d. C. hasta el comienzo del siglo $\vee$ d. C. Las piezas a destacar son una sudgálica Drag. 27 (época Claudio-Domiciano), una clara A H-31 (época de los Severos), una clara C H-50 (aproximadamente desde mediados del ill y durante todo el siglo iv) y una Clara $\mathrm{C} \mathrm{H}-59$ (del siglo iv y hasta comienzos del v).

\section{C) Balneario de La Pestosa}

La ruina amenaza a todo el conjunto del abandonado balneario. De lo que fue el casino, el comedor, la recepción, las cocinas, las cuadras y las habitaciones y baños para los visitantes y huéspedes, no quedan más que escombros y desorden. Algunas bañeras y conducciones de agua aún se descubren entre los derrubios.

Es interesante el topónimo Fuente de la Laguna. Se trata de un manantial que brota a unos $250 \mathrm{mts}$ al $\mathrm{W}$ de los edificios ruinosos. Muy pro- 
bablemente en épocas geológicas, e incluso prehistóricas, existió allí una laguna o almarjal repleto de vida. El hallazgo de algunas piezas líticas del Paleolítico Inferior realizadas en cuarcitas, denota cierta similitud con la Fuente de Hellín en esta localidad. Las investigaciones demostraron que hubo también un lago de no mucha extensión, pero con suficiente caudal y profundidad, en Hellín.

En la vertiente oriental de la Sierra de Abenuj se distinguen asentamientos y poblados de la época del Bronce Plenc, seguramente atentos a las posibilidades cinegéticas y de plantas textiles que ofrecía la laguna.

La presencia romana no se constata en las inmediaciones de la fuente de la Pestosa o de La Laguna. La razón pudo estar precisamente en la humedad y en las enfermedades que emanaban y se producian en las cercanías de la masa de agua, encerrada en un área endorreica. Acaso por ello, los romanos prefirieron el asentamiento de El Polope ${ }^{46}$, donde la inclinación del terreno permite el desagüe y por donde pasaba una importante vía romana hacia Peñas de S. Pedro. La distancia entre la Pestosa y Polope es de apenas dos kilómetros. Esto permitiría aprovechar las ventajas hidroterápicas de las aguas que tratamos, sin las molestias de vivir en un paraje insalubre y encharcado permanentemente.

Los materiales romanos corresponden a época Altoimperial.

\section{D) Balneario de Santa Quiteria}

Hoy en día del antiguo balneario sólo quedan unas habitaciones incluidas dentro de un caserío aún con vida y en producción. El pozo de donde se extraía el agua todavía se muestra. Pero la ermita, aunque se mantiene en pie, está reutilizada como almacén. Toda función mágica o religiosa se ha perdido y olvidado.

Cerca del conjunto descrito se instaló una importante villa romana en dirección Oeste. En ella se hallaron numerosos fragmentos de mosaicos, de mármoles, de conducciones de plomo para el agua,... etc. LóPEZ Precioso ${ }^{47}$ indica que hubo alli unas termas (hoy destruidas por obras públicas). El autor fecha los materiales en época Altoimperial.

\footnotetext{
${ }^{46}$ Los materiales fueron prospectados en 1982 por los autores; sin embargo el mayor porcentaje de hallazgos han sido obtenidos por GARCIA BLȦZQUZ, L. A. quien amablemente nos ha proporcionado atenta información sobre ellos.

${ }^{47}$ López Precloso, J., Vias de comunicación romanas en la provincia de Albacete. (En prensa). Agradecemos a nuestro amigo la información desinteresada que nos ha proporcionado aún sin ver la luz su obra.
} 
E) Otras fuentes (no termales) de gran importancia con asentamieritos romanos

Para completar el tema del trabajo es muy sugerente citar algunas fuentes de gran caudal, permanente siempre, que fueron ampliamente utilizadas por los romanos como base de explotación agropecaria y artesanal y como sustento fundamental de la vida doméstica.

FUENTE DE HELLIN ${ }^{48}$

En la antigua y pequeña vega del nacimiento se instaló un asentamiento romano de suma importancia a tenor de los mosaicos, de los molinos de cereal, de los hornos y cerámica y de vidrio y de la frecuencia de las sigillatas: sudgálicas, hispánicas, claras $A$ y algo de claras $C$. En la villa se distinguieron un sector de servicios dedicado a talleres artesanales y residencia de colonos o indígenas y otro sector residencial que corresponde a la zona de hallazgos de los mosaicos. En el área de trabajo se recogieron decenas de dolias, de pesas de telar y de rocas industriales, asi como multitud de fragmentos de cerámicas pintadas de tradición indigena. El conjunto muestra una ocupación que abarca desde los inicios del siglo । d. C. hasta los comienzos del siglo III d. C.; si bien el máximo esplendor de esta villa hay que situarlo entre los siglos I y II.

FUENTE DE ISSO ${ }^{49}$

Aprovechando los hilos de agua procedentes de la laguna del ToladiIlo, al $\mathrm{N}$ del pueblo Isso, se instalaron dos villae romanas: la de Prao de Isso y la de la Casa Grande. Hay que incluir también un pequeño asentamiento ibérico con perduración en la fase de la presencia romana (Arroyo Isso-1).

La villa del Prao de Isso ofrece molinos de cereales, posibles prensas de aceite, pavimentos de opus signinum, cerámicas de cocina (morteros, ollas, cazuelas, cuencos, tapaderas), fragmentos de dolia, de pondera, cerámicas pintadas de tradición indígena,... etc. Las sigillatas representadas

48 Ramallo Asensio, S. y Jordan Montes, J. F., La villa romana de Hellín. Contribución al estudio de mundo romano en el Alto Segura. Murcia 1985. Pero ver también el interesante trabajo de Garcia BLAzQuez, L. A., «Informe preliminar de la I y Il campaña de excavación arqueológica en la villa romana de Hellín (Albacete)", fas Jornadas de Historia de Hellín, $\uparrow 987$ (Inéditas).

49 Prospecciones realizadas en 1982 por el equipo y en 1987 por García BLȦzQuez, L. A., "Villas romanas del área fluvial del rio Mundo: Agra Vieja e Isso (Hellín, Albacete)". ${ }^{a s}$ Jornadas de Historia de Hellín, 1987. Pese a estar inéditas el autor nos permitió consultar dudas y resolver cuestiones en su manuscrito. Desde aqui le reiteramos su amable ayuda. 
son las sudgálicas (Drag. 27 y 29), hispánicas (Drag. 15/17 y 35) y claras A. Hay también vestigios de piezas de Rojo Pompeyano (Vegas 15). La fundación del enclave parece corresponder a la época de Augusto y perdura hasta el siglo III d. C.

Sin duda, esta villa explotó agrícolamente la pequeña pero feraz vega de El Prao, situada a unos centenares de metros al Este.

La villa de la Casa Grande de Isso, ya en dirección hacia el río Mundo, mostró en la prospección sepulturas excavadas en la roca. En cuanto al material cerámico aparecieron las clásicas cerámicas de cocina, dolia, tapaderas de ánforas,... etc. Las sigillatas estaban representadas por las clara A (H.14c). Es interesante destacar el topónimo de «Las columnas» en aquel paraje.

El pobladito (Arroyo Isso- 1) denota una larga ocupación: cerámicas ibéricas, aretinas (Goud. 28 y 36), paredes finas (V. 33b), sudgálicas, clara A, C y D. El conjunto abarca, en consecuencia desde el siglo । a. C. hasta el iv d. C., al menos.

FUENTE DE AGRA ${ }^{50}$

Al Sur de la actual aldea de Agra hubo en su tiempo una zona húmeda de gran extensión con varios y caudalosos nacimientos. Aprovechando la rica vega se levantó una villa romana. GARCIA BLANQUEZ estima que existió en ella una instalación termal. Los materiales corresponden a cerámicas pintadas de tradición indigena, a piezas comunes de cocina y a sigillatas: hispánicas (Drag. 15/17), clara C y clara D (H. 61 A). La ocupación se mantuvo probablemente desde finales del siglo I d. C. hasta, acaso, comienzos del $\vee$ d. C.

\section{LA SEDUCCIÓN DE LAS AGUAS SALUTIFERAS Y TERMALES}

Cuando a comienzos de la década de los noventa se concluyó un estudio etnográfico en la serranía de Yeste y Nerpio, realizado en aldeas y comunidades campesinas en áreas de repliegue, ya se apreció el valor extraordinario que el agua conservaba en la mentalidad de las gentes de

${ }^{50}$ Cf. nota 49 . 
montaña ${ }^{51}$. En aquellas localidades el agua de ciertas cumbres (Calar del Mundo), en forma de nieve, adquiría magníficas propiedades salutíferas. Las aguas de los ríos, recogidas en determinadas fechas sacralizadas, y siempre antes de la salida del sol, también manifestaban unas posibilidades únicas para sanar y curar. Sin duda nos hallamos ante reminiscencias prehistóricas mantenidas, prácticamente intactas, durante la romanización, la presencia del Islám y a través de la Baja Edad Media y Edad Moderna.

Las aguas termales no escaparon de la predilección del ser humano. Consideramos de sumo interés haber hallado una necrópolis, aún por excavar, del mundo ibérico junto al nacimiento de agua caliente del Cenajo. Los materiales ibéricos más antiguos, fechados por las piezas áticas de Barniz Negro, nos indican finales del siglo $v$, perdurando la tradición durante todo el siglo IV. Es verdad que no podemos deducir rituales concretos en la incineración pero el hecho de que haya un nexo entre el enterramiento y el manantial termal es de lo más sugerente y atractivo y habla de una intencionalidad evidente.

La presencia romana, incontestable en las proximidades de los cuatro balnearios, también nos narra una selección por parte de los latinos y de los dueños de las villae, de parajes considerados idóneos, bien por las posibilidades de riego que ofrecian los nacimientos, bien por la oportunidad de crear edificios e instalaciones de esparcimiento y relación social (termas). No hay que descartar que en algún caso, dichas fuentes termales sirvieran también como área de descanso en una vía romana o ruta y que en dicho espacio se construyera una mansio o una mutatio. Las villae del Azaraque, del Cenajo, de Polope o de Santa Quiteria nos indican un asentamiento romano desde el siglo । d. C. hasta inicios del siglo $\mathrm{V}$ d. C. E, insistimos, todas ellas construidas y mantenidas junto a fenómenos de termalismo o de aguas salutíferas.

La vinculación de las casas de campo romanas con los manantiales, se refrenda, como ya indicamos, por toda una serie de villae que fueron levantadas junto a fuentes de caudal abundante e incesante: villa del Prao de Isso, de Agra, de Hellín,... etc. En estos últimos casos no había termalismo en las aguas.

Desconocemos a ciencia cierta si los árabes reocuparon los puntos con agua caliente. La toponimia (ya que la prospección de esa fase cultural se encuentra solo en los inicios), nos ayuda parcialmente. Cerca del

\footnotetext{
57 Jordan Montés, J. F. y de la Peña Asencio, A., Mentalidad y tradición de la sierra de Yeste y Nerpio. (En prensa por el I.E.A.).
} 
Cenajo aparece el topónimo «los arrayanes». El mismo Azaraque es vocablo árabe que significa "el surtidor". Muy cerca del balneario de La Pestosa surge el topónimo de montaña «Abenux», de significado incierto. A su vez, el balneario de Santa Quiteria, y toda la huerta de Tobarra, se haya rodeado de nombres árabes: «Aljubé» y «Alboraj» («El pozo» y «La torre», respectivamente). Es, en consecuencia, muy necesaria una prospección metódica de materiales hispanomusulmanes, para verificar y confirmar lo que se puede considerar como un indicio probable: que la cultura árabe en la región reutiliza los nacimientos termales o mineromedicinales. Es más difícil precisar si únicamente como agua de regadío o como elemento de curación en ciertas enfermedades.

Sin embargo, el relato que se lee en las Relaciones Topográficas de Felipe II acerca de las propiedades curativas de las aguas de Santa Quiteria, anima a pensar que la noticia del siglo Xvı no hace sino continuar y recoger costumbres y creencias bajomedievales, al menos.

No obstante, la explotación científica y comercial de los balnearios se inicia bastante más tarde, en concreto hacia mediados del siglo XVIII, cuando Cerdán analiza las aguas del Azaraque por primera vez y describe el ritual de los baños y de las inmersiones. Durante todo el siglo xIx, a tenor de las informaciones proporcionadas, entre otros, por Miñano, Tomás López, Madoz, etc., la vida de los balnearios se mantuvo con fuerza pero no estaba exenta de numerosas deficiencias técnicas y sanitarias y carecia de inversiones que garantizaran una continuidad rentable. Ante la competencia de los balnearios de Murcia, los del SE de la provincia de Albacete, decaen con rapidez y pierden la clientela salvo la que esporádicamente afluye desde el ámbito local.

Consideramos de interés resaltar una posible relación entre manantiales termales y mineromedicinales con la aparición de las célebres encantadas ${ }^{52} \mathrm{o}$ con la manifestación de la Virgen. La encantada de Camarillas, en el río Mundo, parece vincularse al eremitorio ${ }^{53}$ allí abierto

${ }^{52}$ El tema de las encantadas ha sido ampliamente tratado por numerosos autores en el campo de la historia de las religiones y de la etnografia. Por lo general, el relato describe el encuentro entre una joven que peina sus cabellos con un peine de oro (o se contempla en un espejo de oro), con un caminante, por lo común, joven también y de sexo masculino. La encantada siempre hace una pregunta y plantea una elección al varón: si prefiere a ella o al objeto que manipula. Invariablemente el joven elige el objeto y provoca, con esa opción, que la encantada permanezca en su estado otro tiempo determinado; un siglo casi siempre.

53 Gonzalez Blanco, A.; Lillo Carpio, P. y Selva iniesta, A., «la cueva de la Camareta, eremitorio cristiano", Congreso de Historia de Albacete. Vol. I: Arqueología y Prehistoria. Albacete 1983, págs. 331 ss. Albacete 1984. 
en la roca blanca y acaso también a la villa romana de El Saltador ${ }^{54}$. La encantada del Cenajo surge precisamente en el paraje del nacimiento termal y coincide con la anterior en que su manifestación se produce junto a los blancos faraliones que bordean un rio, oradados por covachas, repletos de cornisas y con rezumadores en las paredes naturales. La similitud es tal que también existe una villa romana, ya comentada en este trabajo.

La encantada del Tolmo de Minateda se comprende por el arroyo de Tobarra y por la ciudad ibero-romana del Tolmo de Minateda ${ }^{55}$.

La encantada del Castellar de Sierra se entiende al haber allí una ciudad hispanomusulmana en ruinas, con una vieja fortaleza ${ }^{56}$.

Por último, la de Isso también se manifiesta en los restos de una castillo hispanomusulmán y, acaso, con las villae de El Prao y de Casa Grande.

En definitiva, pensamos que hay indicios sugerentes para suponer, en algunos casos, una identidad entre encantada y agua termal o villa romana, en especial si estimamos a las encantadas como reminiscencias de antiguas ninfas de las aguas. La creencia de la aparición de la Virgen Santa Quiteria, junto a una villa romana y a un manantial mineromedicinal, se puede insertar en un proceso de cristianización en el que se produce la sustitución de una ninfa y su leyenda por un relato católico ${ }^{57}$.

${ }^{54}$ Jordan Montes, J.; Ramallo Asensio, S. y Selva Iniesta, A. «El poblamiento romano en el valle de Minateda-Agramón», Congreso de Historia de Albacete. Vol. I (Op. Cit.), págs. 224-225.

${ }^{55}$ BreulL, H. y LANTIER, R., "Villages pre-romaines de la Peninsule Iberique. Le Tolmo à Minateda". Archivo de Prehistoria Levantina Vol. II. Valencia 1945, págs. 213-238.

${ }^{56}$ Cf. Nota 43. Pero añadir además, Montano Algaba, P., «Apuntes de arqueología. El Castellar de Sierra (Tobarra-Albacete)». Revista de Estudios Tobarreños, n. ${ }^{\circ}$, págs. 9-40, Tobarra 1989.

${ }^{57}$ Dichos procesos de cristianización ya fueron estudiados en las ermitas de la región. Es más, las ermitas con suma frecuencia fueron levantadas junto o sobre villae romanas: la de Camarillas, la de Minateda, Agra, Santa Quiteria,... JoRDAN MonTES, J. F., «Las ermitas en la comarca de Hellín-Tobarra. Ejemplo de cristianización de espacios sacros", IV Jornadas de Etnología de Castilla-La Mancha. Albacete 1986, págs. 411-437. Toledo 1987. 


\section{EVOLUCIÓN CRONOLÓGICA DE LOS BALNEARIOS}

\begin{tabular}{|c|c|c|c|c|c|c|}
\hline año 1500 & $\begin{array}{r}\text { S.XvI } \\
\ldots \ldots \ldots \ldots\end{array}$ & S.XVII & s.XVIII & $\begin{array}{r}\text { S.Xix } \\
\ldots \ldots \ldots \\
\end{array}$ & $\begin{array}{r}\text { s.xx } \\
\ldots \ldots \ldots\end{array}$ & $\ldots .2000$ \\
\hline Azaraque: & & & $(1745)$ & - n & - & (1963) \\
\hline Cenajo: & & & & $? \ldots \ldots$ & ........ ----- & $(1945)$ \\
\hline Pestosa: & & & & & (1905) & (1935) \\
\hline Sta. Quiteria: & $\begin{array}{c}? \ldots \ldots \ldots \\
(1576)\end{array}$ & ----- & 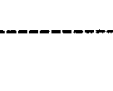 & ---- & 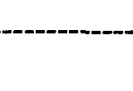 & $(1925)$ \\
\hline
\end{tabular}

\section{RESUMEN}

El trabajo analiza desde múltiples perspectivas un conjunto de viejos balnearios, hoy en ruinas, en el valle bajo del río Mundo (provincia de Albacete). Los enfoques desde la geología, geografía, historia, arqueologia y etnografia, permiten alcanzar una visión amplia e integradora.

Se pretende resaltar la continuidad en la utilización de las aguas termales desde el mundo ibérico hasta finales de la presencia romana en la Península. E igualmente recordar la importancia social y económica que los balnearios adquirieron durante el siglo xIx y prinçipios del xx.

\section{ABSTRACT}

This work analyses a group of ancient spas, which are in ruins today, located on the low valley of the Mundo River (Region of Albacete) from different points of view. We can reach a wide an integral view from the Geology, Geography, History, Archeology and Ethnography approaches.

We try to point out that thermal waters have been used from the Iberic world until the end of the Roman occupation of the Peninsula. And also to remember both the social and economic importance that these spas reached during the $19^{\text {th }}$ an also the beginning of the $20^{\text {th }}$ century. 